\title{
Base-Catalyzed Rearrangement of Some 1,3-Oxathiolane Sulfoxides: Mechanistic Viewpoint of the Sigmatropic and Elimination Reactions
}

\author{
Hoh-Gyu Hahn, Kee Dal Nam, and Seung Hoon Cheon" \\ Organic Chemistry Lah. Korea Institute of Science and Technolog, P.O. Box 131, Cheongryang, Seoul 136-650, Korea \\ ${ }^{\circ}$ College of Phamacy, Chomam National liniversity; Kwang-.Ji 500-757, Korea \\ Received April 14, 2004
}

\begin{abstract}
Rearrangements of 1,3-oxathiolane sulfoxides $\mathbf{8}$ and 9 in the presence of base are described from a mechanistic viewpoint of sigmatropic and elimination reactions. In the presence of triethylamine the $(Z)$ sulfoxide 8 gave the corresponding thiolsulfinate $\mathbf{1 0}$ by way of dimerization of the sulfenic acid intermediate 2 at room temperature while the $(E)$-sulfoxide 9 was recovered even after refluxing in ethyl acetate by the reversal of the [2.3]-sigmatropic rearrangement of the sulfenic acid 4 . Triethylamine promoted the developing charge separation in the transition state of the sigmatropic rearrangement of the (Z)-sulfoxide 8 to facilitate the ring opening to the sulfenic acid 2 . The reason for more facile ring opening of the (Z)-sulfoxide 8 in comparison with the corresponding (E)-sulfoxide 9 is attributable to the differences in the reactivity of the hydrogen adjacent to the carbonyl group. Triethylamine was not strong base to deprotonate the carbonyl-activated methylene hydrogen of the $(E)$-sulfoxide 9 but enough to catalyze the sigmatropic process of the sulfoxides. The sulfenic acid $\mathbf{2}$ dimerized to the thiolsulfinate $\mathbf{1 0}$ while the sulfenic acid $\mathbf{4}$ proceeded the sigmatropic ring closure. In the presence of strong base such as potassium hydroxide, the elimination reaction was predominant over the sigmatropic rearrangement. In this reaction condition, both sulfoxides $\mathbf{8 a}$ and $9 \mathbf{a}$ gave a mixture of the disulfide 12, the isomeric disulfide $\mathbf{1 4}$. and the sulfinic acid 13. Under the strong alkaline condition an elimination of activated hydrogen from the carbon adjacent to the carbonyl group to furnish the sulfenic acid $2 \mathbf{a}$ and the isomeric sulfenic acid 18 . The formation of the transient intermediate in the reaction was proven by isolation of the isomeric disulfide $\mathbf{1 4}$. The reactive entity was regarded as the sulfenic acid rather than sulfenate anion under these reaction conditions.
\end{abstract}

Key Words : Sigmatropic reatrangement. Sulfoxide. Sulfenic acid, Thiolsulfinate, Sulfinic acid

\section{Introduction}

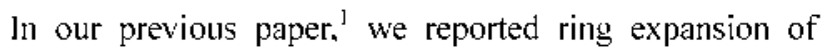
1,3-oxathiolane sulfoxide 1 to dihydro-1,4-oxathiin 3 or 5 via sulfenic acid $\mathbf{2}$ or $\mathbf{4}$, respectively under the acidic or neutral conditions. Under neutral condition, the ring opening reaction proceeded by a [2.3]-sigmatropic process depending on the stereochemistry of the sulfoxide. However, in the presence of acid catalyst the sulfoxide $\mathbf{I}$ gave $\mathbf{3}$ exclusively through the sulfenic acid 2 . As an extension of these studies on the sigmatropic rearrangement of these sulfoxides and on the reactivity of the sulfenic acids, we now report base catalyzed rearrangement of the 1,3-oxathiolane sulfoxide 1 . An important feature of the 1,3-oxathiolane sulfoxide $\mathbf{1}$ is the presence of both carbonyl-activated methylene and unactivated methyl hydrogens $\beta$ to the sulfoxide and the $\mathrm{S}-\mathrm{C}$ bond being ruptured to give the corresponding sulfenic acids 2, and 4. It is interesting to investigate whether the ring opening reaction of $\mathbf{1}$ takes place or not in the presence of base catalyst and it is also interesting to find out that the reactivity of the feasible intermediates of sulfenic acids (c.g. $2,4)$ under these reaction conditions.

\section{Results and Discussion}

The starting 1,3-oxathiolane sulfoxides were prepared by the previously reported method (Scheme 1). ${ }^{2}$ Hemithioketalization of $\beta$-keto acid derivatives 6 with 2 -mercaptoethanol gave 1,3-oxathiolanes 7 . Oxidation of 7 using $30 \%$ aqueous hydrogen peroxide in the presence of benzeneseleninic acid catalyst or m-chloroperbenzoic acid gave a mixture of the $(C)$-sulfoxide $8(2 S R, 3 R S)$ as a major and the (E)-sulfoxide

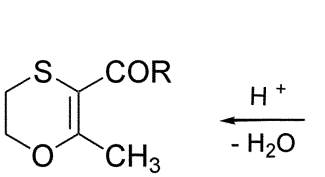

3<smiles>[R]O/C=C(/C)OCCSO</smiles>

2

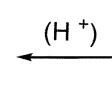

a, $\mathrm{R}=\mathrm{NHC}_{6} \mathrm{H}_{5}$<smiles>[R]OCC[C@@]1(C)OCC[Si]1O</smiles>

1

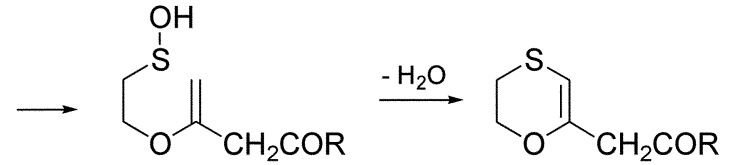

4 
<smiles>[R]C(=O)CC(C)=O</smiles>
6<smiles>[R]C(=O)CC1(C)OCCS1</smiles>

7

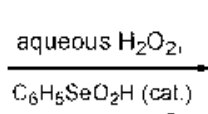

$\mathrm{CH}_{2} \mathrm{Cl}_{2}, 15-20^{\circ} \mathrm{C}$<smiles>[R]OCC[C@]1(C)OCC[S@]1=O</smiles>

(Z)<smiles>[R]C(=O)C[C@]1(C)OCC[S@]1=O</smiles>

(E)

9 (2RS, 3RS)

$$
\begin{aligned}
& \text { a, R }=\mathrm{NHC}_{6} \mathrm{H}_{5} \\
& \text { b. } \mathrm{R}=\mathrm{OCH}_{3}
\end{aligned}
$$

\section{Scheme 1}

$9(2 R S, 3 R S)$. These ( $Z$ )-sulfoxy anilide 8a and $\left(E^{\prime}\right)$-sulfoxy anilide 9a were separated by either fractional crystallization or chromatography. The sulfoxy ester was synthesized from the oxidation of the corresponding sulfide $7 \mathbf{b}$ by the similar method. Actually, the ( $Z$ )-sulfoxy ester $\mathbf{8 b}$ could not be isolated due to its instability while the $(E)$-sulfoxide $9 \mathbf{b}$ was fairly stable at room temperature.

Rearrangement of $(Z)-8$ and $(E)-9$ Sulfoxides in the Presence of Triethylamine. In general, a sulfenic acid is unstable and dimerizes to a thiolsulfinate with a loss of water due to the dual characteristics of a sulfenic acid as $S$ nucleophile/S-electrophile." As shown in Scheme 2 when the $(Z)$-sulfoxy anilide 8 a was treated with triethylamine or potassium acetate in either ethyl acetate or methylene chloride at room temperature gave the thiolsulfinate 10a ( $83 \%$ yields). In the absence of triethylamine, the ( $Z$ )sulfoxy anilide 8a decomposed slowly to a complex mixture containing acetoacetanilide at rom temperature, presumably by the action of trace amount of water and acid in the medium. In case of methyl ester, we could not isolate the ( $C$ )-sulfoxy ester $\mathbf{8 b}$ due to its instability (vide stura). Instead, immediate treatment of the freshly prepared mixture of $\mathbf{8 b}$ and $\mathbf{9 b}$ with triethylamine at room temperature afforded a mixture of the corresponding thiolsulfinate $\mathbf{1 0 b}$ and $\mathbf{9 b}$. Apparently, the (Z)sulfoxy ester $\mathbf{8 b}$ transformed smoothly to the thiolsulfinate $\mathbf{1 0 b}$ while the $(E)$-sulfoxy ester 9b was fairly stable in this reaction condition. The probable reaction pathway leading to the thiolsulfinate $\mathbf{1 0}$ from the $(Z)$-sulfoxides $\mathbf{8}$ begins with ring opening of the $(Z)$-sulfoxide 8 through the $[2,3]$-sigmatropic rearrangement involving carbonyl-activated methylene hydrogen followed by dimerization of the sulfenic acid intermediate 2. Possibly, the reason for more facile ring opening of the ( $Z$ )-sulfoxy ester $\mathbf{8 b}$ (below room temperature) in comparison with the corresponding $\mathbf{8 a}$ is attributable to the differences in the reactivity of the hydrogen adjacent to the carbonyl group. Presumably, triethylamine or potassium acetate promoted the developing charge separation in the transition-state (TS) to facilitate the ring opening of the ( $\angle$ )sulfoxide $\mathbf{8}$ to the sulfenic acid 2 . Similar results were obtained by using of either inorganic salts such as sodium bicarbonate, sodium carbonate and potassium carbonate or weak organic base such as pyridine instead of triethylamine. In contrast. the (E)-sulfoxy anilide 9a and ester 9b were fairly stable at room temperature under the same condition and recovered completely even after heating at reflux in ethyl acetate or benzene in the presence of triethylamine.

The deuterium incorporation reaction ${ }^{1}$ of the $(E)$-sulfoxide 9 suggests that this sulfoxide is converted to the sulfenic acid 4 by the ring opening at this temperature but the sulfenic acid 4 cyclized back to the $(E)$-sulfoxide 9 without formation of the corresponding thiolsulfinate 11. Probably, the higher pi-electron density of the isolated double bond in the sulfenic acid 4, in comparison with the carbonyl deactivated double bond in the sulfenic acid 2, facilitates the $[2,3]-$ sigmatropic ring closure to the $(E)$-sulfoxide 9 . It seems likely that triethylatnine was not strong base to deprotonate the carbonyl-activated methylene hydrogen of the $(E)$ sulfoxide 9 but enough to catalyze the sigmatropic process of the sulfoxides.

Rearrangement in the Presence of Potassium Hydroxide. Either the (Z)-sulfoxide 8a or the (E)-sulfoxide 9a was subjected to an aqueous solution of potassium hydroxide in<smiles>[R]OC1[C@H]2C=C[S@@]1(=O)OCC2</smiles>

(Z) 8<smiles>[R]OC[C@]1(C)OCC[S@@]1(=O)O</smiles>

(E) 9

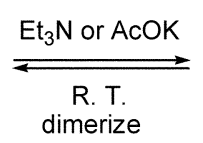

$\mathrm{Et}_{3} \mathrm{~N}$ or $\mathrm{AcOK}$

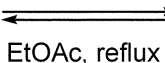

EtOAc, reflux<smiles>CC(=O)C=C1OCCS1([O-])[O-]</smiles>

2<smiles>[R]OCC1=CC(=O)S(=O)OC1</smiles>

4<smiles>[R]C(=O)C=C(C)OCCSS(=O)CCOC(C)=CC([R])=O</smiles>

10

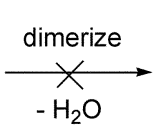<smiles>[R]C(=O)CC(=C)OC</smiles>

a, $\mathrm{R}=\mathrm{NHC}_{6} \mathrm{H}_{5}$

b, $\mathrm{R}=\mathrm{OCH}_{3}$

Scheme 2 
(Z) $\mathbf{8 a}$ or $(E) \mathbf{9 a}$

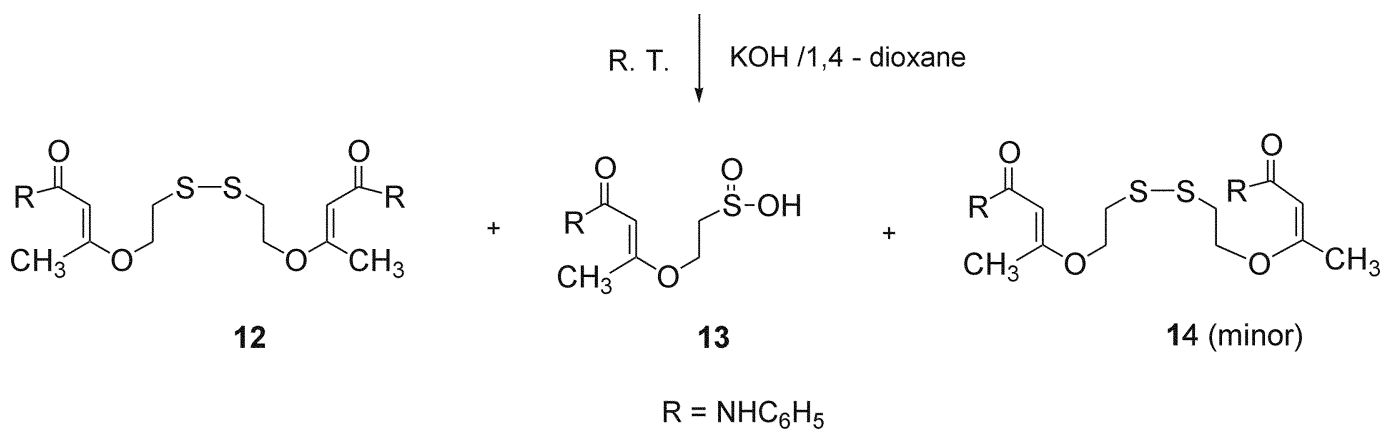

Scheme 3

dioxane to afford a $3: 2$ mixture of a disulfide 12 and sulfinic acid $\mathbf{1 3}$ in addition to a small amount (less than $10 \%$ ) of isomeric disulfide 14 (Scheme 3).

Probably, in the presence of potassium hydroxide the elimination reactions were predominant over the sigmatropic rearrangement of both sulfoxides. Thus, hydroxide ion attacked the carbonyl-activated methylene hydrogen initially regardless of the stereochemistry of the sulfoxides. The elimination reactions may proceed wia TS involving the anti arrangement between departing proton (carbonyl-activated methylene hydrogen) and leaving of $\mathrm{C}-\mathrm{S}$ bond. As shown in Scheme 4, two TS are possible for each sulfoxide. For the (Z)-sulfoxide 8a, conformation 15 is more preferable than 17 due to the unfavorable steric repulsions between the bulky carboxanilide group and the oxathiolane ring. Similarly, 16 is more favorable than 19 in case of the $(E)$-sulfoxide 9 a. The predominant conformations 15 and 16 result the sulfenic acid 2a, and the less favorable contormations 17 and 19 give the isomeric sulfenic acid 18. Apparently, the disulfide 12 and sultinic acid 13 were derived from the sulfenic acid 2a (vide infra) fiom a viewpoint of configuration of double bond of these molecules and the isolation of a minor product, isomeric disulfide $\mathbf{1 4}$ was clear evidence for generation of the isomeric sulfenic acid $\mathbf{1 8}$ from the reactions.

The reaction mechanism can be explained briefly as follows. Both sulfoxides can be initially transformed into the sulfenic acid 2a as a major and the isomeric sulfenic acid $\mathbf{1 8}$. major and minor respectively in the presence of potassium hydroxide in aqueous dioxane. These sulfenic acids would initially dimerize by themselves or react with each other with loss of water, ${ }^{5}$ or sulfenic acid-thiolsulfinate exchange ${ }^{6}$ to give the four different thiolsulfinates as transient intermediates in this reaction condition, which were easily bydrolyzed to give the corresponding disulfides and sulfinic acids. ${ }^{8}$ Actually, we isolated the disulfide 12, the sulfinic acid 13 , and the isomeric disulfide 14 from the reaction of both sulfoxides as depicted in Scheme 3. Undoubtedly, 12 and $\mathbf{1 3}$ are derived from the sulfenic acid $2 a$, and $\mathbf{1 4}$ is formed by condensation reaction of $2 \mathbf{a}$ and isomeric sulfenic acid 18 from a viewpoint of configuration of double bond of the products. However, neither likely disulfide nor the sulfinic acid (not shown) derived from dimerization of 18 could be found, probably due to the relatively unfavorable formation of 18 from the reaction. The disulfide 12 and the isomeric disulfide 14 were separated by preparative TI.C.

The disulfide 12 had an identical ' $H$ NMR spectrum and mp with those obtained previously and the structure of new

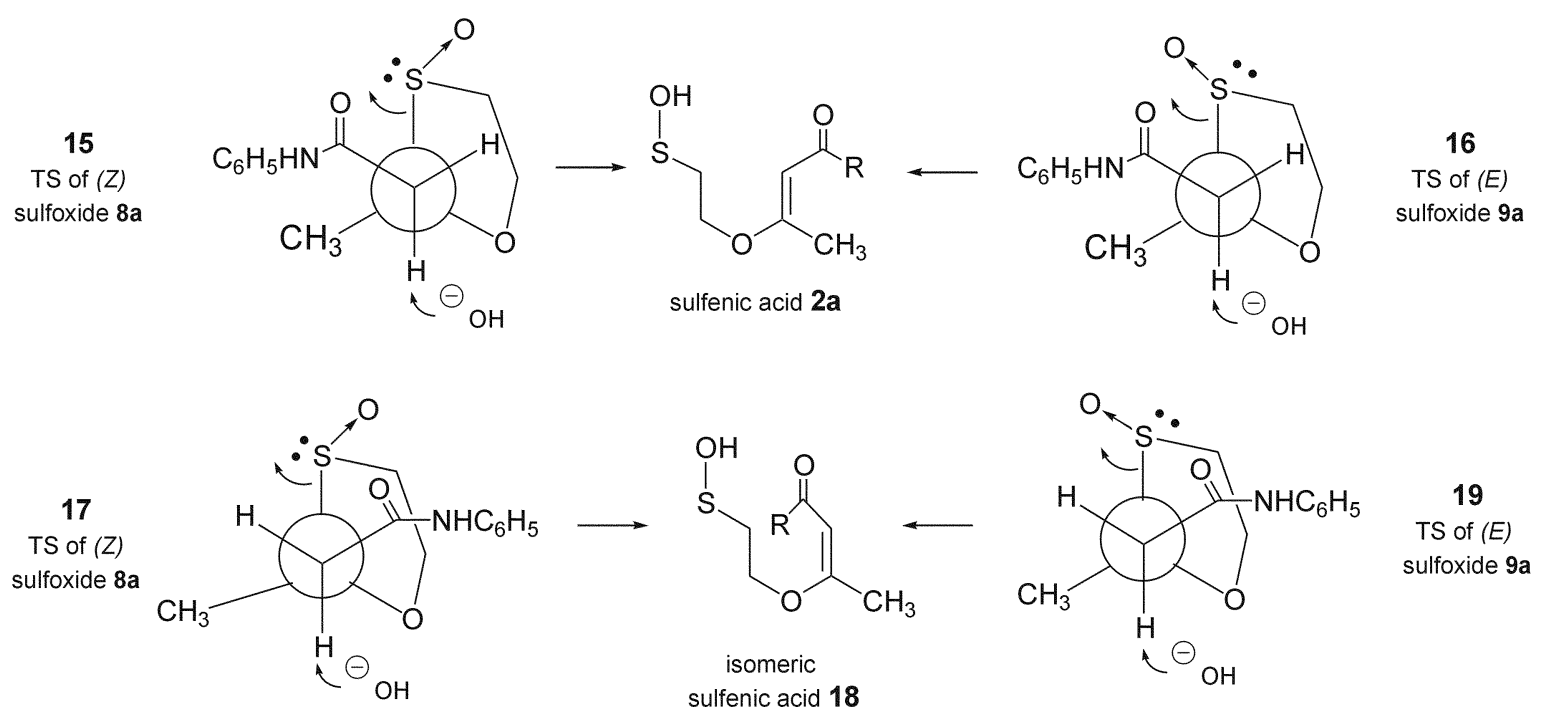

Sclieme 4 


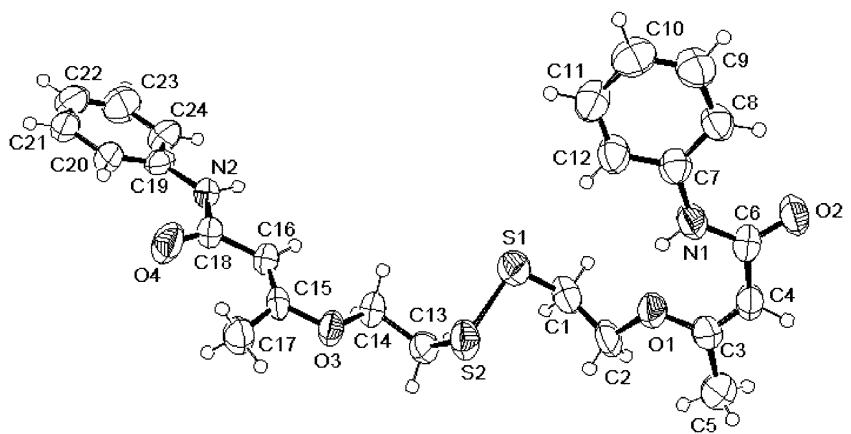

Figure 1. ORTLEP plots of isomeric disulfide 14 with heteroatoms labcled.<smiles>[R]C(=O)/C=C(/C)OCCS(C)(=O)=O</smiles>

20

21

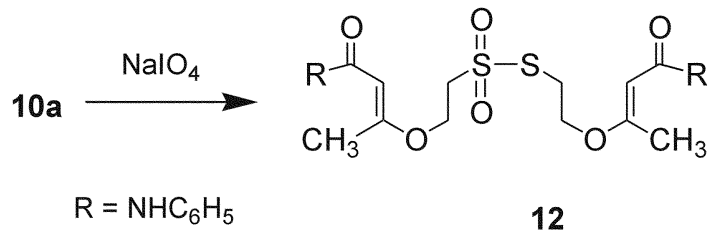

Scheme 5

isomeric disulfide 14 was confirmed by ${ }^{1} \mathrm{H}$ and ${ }^{1.7} \mathrm{C}$ NMR, IR, MS spectra. elemental analysis data, and finally by the X-ray crystallographic analys is (Figure 1). Comparing their 'H NMR spectra, four triplets at $2.93,3.07,3.94,4.39 \mathrm{ppm}$ for methylene protons and two singlets at $4.91,5.13 \mathrm{ppm}$ for vinyl protons were shown for 14 while two triplets at $\delta 3.04,4.07$ ppm for metlyylene protons and one singlet at $\delta 5.12 \mathrm{ppm}$ for vinyl proton for $\mathbf{1 2}$ due to the symmetry of the compound.

The sulfinic acid $\mathbf{1 3}$ was obtained as a white amorphous solid by the acidification of the aqueous layer of the reaction mixture. Although its 'H NMR and IR spectra agreed with the structure, it was ton unstable to purify at room temperature. Therefore, its structure was confirmed by its conversion to thiolsulfone $\mathbf{2 0}$ and methyl sulfinate $\mathbf{2 1}$, by the treatment with methyl iodide ${ }^{\gamma}$ and diazomethane ${ }^{3}$ respectively (Scheme 5). Their spectral and elemental analyses data were agreed with their structures.

Additionally, the probable product," thiolsulfonate $\mathbf{2 2}$ (Scheme 5) could not be isolated from the reaction. For the purpose of comparison, 22 was synthesized independently by oxidation of the thiolsulfinate $10 \mathbf{a}^{10}$

\section{Conclusion}

Sigmatropic rearrangement of the 1,3-oxathiolane sulfoxide was catalyzed by weak base such as triethylamine or potassium acetate, presumably by the promotion of developing charge separation in the transition-state to facilitate the ring opening of the sulfoxide to the corresponding sulfenic acid. The sulfenic acid either dimerize to the corresponding thiolsulfinate or proceed the sigmatropic ring closure depending on the electronic character of the internal double bond in the sulfenic acid. Triethylamine was not strong base to deprotonate the carbonyl-activated methylene hydrogen of the sulfoxide but enough to catalyze the sigmatropic process of the sulfoxides. In the presence of strong base such as potassium hydroxide the elimination was predominant over the sigmatropic process to afford the sulfenic acid as a major and the less favorable conformational isomeric sulfenic acid. The sulfenic acid was regarded as a reactive entity under basic as well as neutral or acidic conditions, and converted to dimerize with loss of water into the corresponding thiolsulfinate. While the thiolsulfinates were fairly stable in the presence of triethylamine, it easily hydrolyzed in the presence of potassium hydroxide to give the corresponding disulfide and the sulfinic acid.

\section{Experimental Section}

Melting points were determined on a Thomas-Hoover capillary melting point apparatus. All ${ }^{1} \mathrm{H}$ and ${ }^{13} \mathrm{C}$ NMR spectra were recorded on a Varian Gemini 300 NMR (300 $\mathrm{MHz}$. for ${ }^{1} \mathrm{H}, 78.5 \mathrm{MH}$. for ${ }^{1.3} \mathrm{C}$ ) or Bruker AM-200 (200 $\mathrm{MHz}$ for ${ }^{1} \mathrm{H}, 50.3 \mathrm{MHz}$ for ${ }^{13} \mathrm{C}$ ) spectrometer, Chemical shift $(\delta)$ are given in ppm and the coupling constants $(J)$ in $\mathrm{H} 7 ., \mathrm{IR}$ spectra were obtained on a Perkin-ГImer 16F-PC FT-IR and are reported in $\mathrm{cm}^{-1}$. MS spectra were recorded on a Hewlet Packard 5890 series GCMSD. HRMS were obtained on a Finnigan MAT95S. Filemental analysis was performed using a Fisons F:A 108 analyzer. All chromatographic isolation was accomplished on silica gel GF254 (230-400 mesh).

Synthesis of thiolsulfinate $10 \mathrm{a}$ by treatment of $(Z)$ sulfoxy anilide 8a with potassium acetate. To a stirred solution of (Z)-sulfoxide 8 a $(5.07 \mathrm{~g}, 0.02 \mathrm{~mol})$ in ethyl acetate $(300 \mathrm{ml}$.) was added potassium acetate $(0.20 \mathrm{~g})$ and allowed to stir at room temperature for 9 days. The white precipitate was filtered to give thiolsulfinate $10 \mathrm{a}(4.04 \mathrm{~g}$. $83 \%$ ). This product had identical melting point, ${ }^{1} \mathrm{H}$ NMR and IR spectra with those of the compound obtained from the preceding paper.'

mp 137-138 ${ }^{\circ} \mathrm{C}$ (crystallized from acetone/cyclohexane); 'H NMR (300 MHz, CDCls) 2.38 (s, 6H, $\left.2 \times \mathrm{CH}_{3}\right), 3.41-$ $3.60\left(\mathrm{~m}, 4 \mathrm{H}, \mathrm{CH}_{2} \mathrm{~S}\right), 4.0 \mathrm{l}-4.15$ and $4.22-4.29(\mathrm{~m}, 4 \mathrm{H}$. $\left.\mathrm{CH}_{2} \mathrm{O}\right), 5.09$ and 5.12 (2s, $2 \mathrm{H}, 2 \times$ vinyl $\left.\mathrm{CH}\right), 7.04-7.55(\mathrm{~m}$. $10 \mathrm{H}, \mathrm{ArH}), 7.20$ and $7.45(2 \times$ br s, $2 \mathrm{H}, 2 \times \mathrm{NH})$; IR $(\mathrm{KBr})$ $1664(\mathrm{C}=\mathrm{C}), 1620(\mathrm{C}=\mathrm{O}), 1076(\mathrm{~S}, \mathrm{O})$.

Synthesis of thiolsulfinate $10 \mathrm{a}$ by treatment of $(Z)$ sulfoxy anilide 8 a with triethylamine. 'To a stirred solution of ( $\angle$ )-sulfoxide 8a (12.65 g, $0.05 \mathrm{~mol})$ in ethyl acetate (600 $\mathrm{mL}$ ) was added triethylamine $(6.97 \mathrm{~mL})$ and allowed to stir at room temperature for 3 days. The white precipitate was filtered to afford thiolsulfinate 10a $(9.07 \mathrm{~g}, 74 \%)$. This product had identical 'H NMR and IR spectra with those of the compound obtained from the preceding experiment.

Synthesis of thiolsulfinate 10b by treatment of a mixture of $(Z)$-sulfoxy methyl ester $8 \mathrm{~b}$ and $(E)$-sulfoxy methyl ester 9b $(7: 3)$ with triethylamine. A freshly 
prepared a mixture of $(Z)$-sulfoxide $\mathbf{8 b}$ and $(E)$-sulfoxide $9 \mathbf{b}$ $(7: 3)(1.20 \mathrm{~g} .6 .24 \mathrm{mmol})$ was dissolved in ethyl acetate $(10$ $\mathrm{mL}$ ) and added triethylamine $(1.74 \mathrm{~mL})$. The reaction mixture was stirred at room temperature for 3 days. Evaporation of the solvent gave a colorless oily residue. The products were separated by preparative TLC using benzene/ ethyl acetate $(7: 3)$ as an eluent. The first and the second bands were extracted with chloroform to give the thiolsulfunate $10 \mathrm{~b}(R f 0.6 .0 .46 \mathrm{~g} .20 \%)$ as colorless oil and the $(E)$-sulfoxide $9 \mathrm{~b}(R f 0.2 .80 \mathrm{mg})$ as colorless oil respectively. These products had identical ${ }^{1} \mathrm{H}$ NMR and IR spectra with those of the compound obtained from the preceding paper. ${ }^{1}$

10b: colorless oil; ${ }^{1} \mathrm{H}$ NMR $\left(300 \mathrm{MHz} . \mathrm{CDCl}_{3}\right) 2.31$ (s. $\left.6 \mathrm{H}, 2 \times \mathrm{CH}_{3}\right) .3 .40-3.58(\mathrm{~m}, 4 \mathrm{H} . \mathrm{CH}-\mathrm{S}) .3 .68\left(\mathrm{~s} .6 \mathrm{H}_{2}, \mathrm{OCH}_{3}\right.$ ). $4.20-4.12$ and $4.18-4.30\left(\mathrm{~m}, 4 \mathrm{H}, \mathrm{OCH}_{2}\right) .5 .03$ and $5.08(2 \mathrm{~s}$. $2 \mathrm{H}, 2 \times$ vinyl CH$) ; \mathrm{IR}(\mathrm{NaCl}) 17 \mathrm{I} 2(\mathrm{C}=\mathrm{O}) .1054(\mathrm{~S} \rightarrow \mathrm{O})$.

9b: colorless oil ${ }^{1} \mathrm{H}$ NMR $\left(300 \mathrm{MHz}, \mathrm{CDCl}_{3}\right) 1.55$ (s, $3 \mathrm{H}$. $\mathrm{CH}_{3}$ ). 2.96 (s. $2 \mathrm{H} . \mathrm{CH}_{2} \mathrm{CO}$ ), $2.90-2.96$ and $3.17-3.28$ (m. $2 \mathrm{H}$. $\left.\mathrm{CH}_{2} \mathrm{~S}\right), 3.70\left(\mathrm{~s}, 3 \mathrm{H} . \mathrm{OCH}_{3}\right), 4.35-4.43$ (m. $2 \mathrm{H}, \mathrm{CH}_{2} \mathrm{O}$ ); IR $(\mathrm{NaCl}) 1740(\mathrm{C}=\mathrm{O}) .1050(\mathrm{~S} \rightarrow \mathrm{O})$.

Treatment of $(Z)$-sulfoxy anilide $8 \mathrm{a}$ with potassium hydroxide. To a stirred solution of $(Z)$-sulfoxide $8 \mathrm{a}(5.07 \mathrm{~g}$. $0.02 \mathrm{~mol})$ in dioxane $(200 \mathrm{~mL})$ was added a solution of potassium hydroxide $(1.12 \mathrm{~g}, 0.02 \mathrm{~mol})$ in water $(40 \mathrm{~mL})$ and allowed to stir at room temperature for $3 \mathrm{~h}$. The solvent was evaporated to give a light yellow gummy. This residue was dissolved in methylene chloride $(200 \mathrm{~mL})$, washed twice with water, and dried over $\mathrm{Na}_{2} \mathrm{SO}_{4}$. The organic layer was evaporated to give a yellow foany solid. as a mixture of disulfide 12. isomeric disulfide 14 , and (Z)-sulfoxide $8 \mathrm{a}$ by TLC. These compounds were separated by preparative TLC using ethyl acetate and n-hexane $(1: 1)$ as eluent. The first band $\left(R_{f} 0.7\right)$. the second band $(R f 0.3)$. and the third band $\left(R_{f}\right.$ $0.1)$ were respectively extracted with chloroform to give $\mathbf{1 2}$ $(715 \mathrm{mg}) . \mathbf{1 4}(124 \mathrm{mg})$, and $8 \mathrm{a}(290 \mathrm{mg})$. The water layer was combined and neutralized with $\mathrm{I} \mathrm{N}$ hydrochloric acid (about $16 \mathrm{~mL}$ ) under ice bath. The white precipitates were collected by filtration and dried at $-20^{\circ} \mathrm{C}$ to obtain sulfinic acid $13(1.76 \mathrm{~g} .35 \%)$. The disulfide 12 had identical mp. ${ }^{~} \mathrm{H}$ NMR and IR spectra with those of the compound obtained from the preceding paper. ${ }^{l}$

Disulfide 12: mp 167-168 ${ }^{\circ} \mathrm{C}$ (crystallized from ethyl acetate/petroleum ether); ${ }^{1} \mathrm{H} \mathrm{NMR}\left(300 \mathrm{MHz} . \mathrm{CDCl}_{3}\right) 2.40$ $\left(3,6 \mathrm{H}, 2 \times \mathrm{CH}_{3}\right) .3 .04\left(\mathrm{t}, 4 \mathrm{H} . J=6.5,2 \times \mathrm{SCH}_{2}\right) .4 .07(\mathrm{t}, 4 \mathrm{H}$. $\left.J=6.5 .2 \times \mathrm{OCH}_{2}\right) .5 .12$ (s. $2 \mathrm{H}$. vinyl CH). 7.07-7.55 (m. 10H. $\mathrm{ArH}$ ), $7.2 \mathrm{l}($ br s, $2 \mathrm{H}, \mathrm{NH})$ : IR (KBr) $1662(\mathrm{C}=\mathrm{O}), 1613$ $(\mathrm{C}=\mathrm{C})$.

Sulfinic acid 13: mp $64-66{ }^{\circ} \mathrm{C}$ (crude product); ${ }^{1} \mathrm{H}$ NMR $\left(300 \mathrm{MHz}, \mathrm{DMSO}-\mathrm{d}_{6}\right) 2.20\left(\mathrm{~s}, 3 \mathrm{H}, \mathrm{CH}_{3}\right), 2.62$ (t, $\mathrm{lH} . J=$ 6.8. $\mathrm{SCH}$ ). $2.73(\mathrm{t}, 1 \mathrm{H}, J=5.9, \mathrm{SCH}), 3.63$ (t. $1 \mathrm{H} . J=6.8$. $\mathrm{OCH}) .3 .69(\mathrm{t} .1 \mathrm{H}, J=5.9 . \mathrm{OCH}), 4.29$ (br s. $1 \mathrm{H}$. $\mathrm{SO}_{2} \mathrm{H}$ ). 7.30-7.58 (m, 5H, ArH), 10.1 (br s. IH. NH); IR (KBr) 3328 $(\mathrm{OH}$ and $\mathrm{NH}), 1669(\mathrm{C}=\mathrm{O}) .1603(\mathrm{C}=\mathrm{C}) .1161(\mathrm{C}-\mathrm{O}-\mathrm{C})$.

Isomeric disulfide 14 : $\mathrm{mp} 115-116^{\circ} \mathrm{C}$ (crystallized from ethyl acetate/petroleum ether): ${ }^{1} \mathrm{H}$ NMR $\left(300 \mathrm{MHz}, \mathrm{CDCl}_{3}\right)$ 2.12 and 2.35 ( $\left.2 \mathrm{~s} .6 \mathrm{H}, 2 \times \mathrm{CH}_{3}\right) .2 .93$ (t. $J=6.0,2 \mathrm{H}$. SCH). $3.07(\mathrm{t}, J=5.5,2 \mathrm{H} . \mathrm{SCH}), 3.94(\mathrm{t}, J=6.0,2 \mathrm{H} . \mathrm{OCH}) .4 .39$ (t. $J=5.5,2 \mathrm{H}, \mathrm{OCH}), 4.9 \mathrm{l}$ and $5.13(2 \mathrm{~s}, 2 \mathrm{H}, 2 \times$ vinyl $\mathrm{CH}$ ), 7.06-7.68 (m. $10 \mathrm{H}$. ArH). 7.58 and $9.17(2 \times$ br s, $2 \mathrm{H} .2 \times$ $\mathrm{NH}):{ }^{12} \mathrm{C}$ NMR $\left(50.3 \mathrm{MHz} . \mathrm{CDCl}_{2}\right)$ 18.55. 18.91, 37.01, $37.98,65.06,65.57 .94 .87,104.38,119.68 .120 .12,123.37$, $123.85,128.75,128.86,138.35,139.04,160.14 .164 .18$, 165.47, 168.92; IR (KBr) I685 (C=O). I646 (C=O): MS (Fast Atom Bombardment Method. Matrix, nitrobenzyl alcohol, ion multiplier voltage. $1.2 \mathrm{KV}$ ) $\mathrm{mz}$ (relative intensity) $473\left(20, \mathrm{M}^{+}+1\right) .236\left(92 .{ }^{-} \mathrm{SCH}_{2} \mathrm{CH}_{2} \mathrm{OC}\left(\mathrm{CH}_{3}\right)\right.$ $\mathrm{CHCONH}_{6} \mathrm{CH}_{5}$ ): Analy sis Calcd for $\mathrm{C}_{24} \mathrm{H}_{28} \mathrm{~N}_{2} \mathrm{~S}_{2} \mathrm{O}_{4}: \mathrm{C}, 61.0$, H. 5.97. N, 5.93. Found. C 60.8 . H. 5.92, N. 5.82 .

Data of X-Ray analysis: The data was collected on an Enraf-Nonius CAD4 automated diffractometer equipped with a Mo X-Ray tube and a graphite monochromator. Triclinic space group Pî with $a=9.248(2) \AA . b=11.485(3)$ $\AA, c=13.707(3) \AA . V=1350.1(5)^{3} . Z=2, d_{c a d c}=1.163 \mathrm{gcm}^{-3}$. $\mu=0.226 \mathrm{~mm}^{-1}$. A total of 2323 independent absorptioncorrected reflections were collected. The structure was solved using SHELXS86 and SHELXL97 programs. The resulting structural parameters were refined to convergence of $\mathrm{Rl}=0.0962$ using full-matrix least-squares tecluniques and a structural model which incorporated anisotropic thermal parameters for all nonhydrogen atoms and isotropic thermal parameters for all hydrogen atoms.

Treatment of $(E)$-sulfoxy anilide $9 \mathrm{a}$ with potassium hydroxide. Similar results were obtained from the treatment of the $(E)$-sulfoxide $9 \mathrm{a}$ with potassium hydroxide under same reaction condition described above. From the reaction of the (E)-sulfoxide 9 a ( $(1.01 \mathrm{~g} .4 \mathrm{mmol}) .12$ (137 mg), 14 $(26 \mathrm{mg}) .9 \mathrm{a}(25 \mathrm{mg})$, and $13(260 \mathrm{mg})$ were obtained. These compounds had identical mp, ${ }^{1} \mathrm{H}$ NMR and IR spectra with those of the compounds obtained from the above reaction.

Preparation of thiolsulfone $\mathbf{2 0}$. To a stirred solution of the sulfinic acid $13(288 \mathrm{mg} .1 .07 \mathrm{nmol})$ in dioxane $(9 \mathrm{~mL})$ and water $(9 \mathrm{~mL})$ was added metlyl iodide $(6 \mathrm{~mL})$ and allowed to stir at room temperature for $1 \mathrm{~h}$. The solvent was evaporated to give an oily residue. This was dissolved in chloroform. washed with water twice. and dried $\left(\mathrm{Na}_{2} \mathrm{SO}_{4}\right)$. The solvent was removed to give a light yellow oily residue, crystallized form chlorofom $/ n$-hexane to obtain $\mathbf{2 0}$ as white

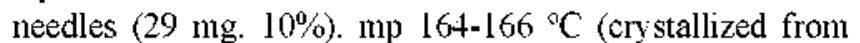
cllorofom/n-hexane): ${ }^{1} \mathrm{H}$ NMR (200 MHz, $\mathrm{CDCl}_{3}$ ) 2.37 (s, $\left.3 \mathrm{H} . \mathrm{CH}_{3}\right) .3 .03$ (s. $\left.3 \mathrm{H}_{2} \mathrm{SO}_{2} \mathrm{CH}_{3}\right), 3.40\left(\mathrm{t}, J=5.4,2 \mathrm{H} . \mathrm{SCH}_{3}\right)$, 4.23 (t. $\left.J=5.4 .2 \mathrm{H} . \mathrm{OCH}_{2}\right), 5.11(\mathrm{~s}, \mathrm{lH}$. vinyl $\mathrm{CH}$ ). 7.09 7.54 (m. $6 \mathrm{H}, \mathrm{ArH}$ and $\mathrm{NH}) ;{ }^{13} \mathrm{C}$ NMR $\left(50.3 \mathrm{MHz}, \mathrm{CDCl}_{3}\right)$ $18.53,42.89$. 54.17. 61.59. 95.41, 120.03. 124.11. 129.02, 138.35, 164.76. 165.14, 168.62: IR (KBr) $3364(\mathrm{NH}), 1678$ $(\mathrm{C}=\mathrm{O}) .1620(\mathrm{C}=\mathrm{C}) .1284$ and $1129\left(\mathrm{SO}_{2}\right): \mathrm{MS}(70 \mathrm{eV}) \mathrm{mz}$ (relative intensity) $283\left(4.2 . \mathrm{M}^{+}\right) .191\left(29.9\left(\mathrm{M}^{-}-\mathrm{C}_{6} \mathrm{H}_{5} \mathrm{NH}\right)\right.$, $107\left(37.5 . \mathrm{CH}_{3} \mathrm{SO}_{2} \mathrm{CH}_{2} \mathrm{CH}_{2}^{-}\right), 83\left(100 .{ }^{+} \mathrm{O}=\mathrm{CCH}=\mathrm{C}\left(\mathrm{CH}_{3}\right) \mathrm{O}\right)$; Analysis Calcd for $\mathrm{C}_{13} \mathrm{H}_{17} \mathrm{~N}_{4} \mathrm{~S}: \mathrm{C}, 55.1, \mathrm{H}, 6.05, \mathrm{~N}, 4.94$. Found, C, 54.7. H, 6.02. N. 4.86.

Preparation of methyl sulfinate 21. To a suspended solution of the sulfinic acid $13(1.35 \mathrm{~g} .5 \mathrm{mmol})$ in icecooled chloroform $(10 \mathrm{~mL})$ was added excess amount of a solution of diazomethane dissolved in ether and allowed to 
stir for $15 \mathrm{~min}$. The solvents were evaporated to give a light yellow solid residue. Crystallization from benzene/petroleum ether gave 21 as colorless plates ( 1.15 g. 81\%). mp 105-107 ${ }^{\circ} \mathrm{C}$ (crystallized from benzene/petroleum ether): ${ }^{1} \mathrm{H}$ NMR (300 MHz. $\left.\mathrm{CDCl}_{3}\right) 2.35\left(3,3 \mathrm{H}, \mathrm{CH}_{3}\right) .3 .00-3.08$ and 3.17$3.26\left(\mathrm{~m}, 2 \mathrm{H} . \mathrm{CH}_{2} \mathrm{~S}\right), 3.84\left(\mathrm{~s}, 3 \mathrm{H} . \mathrm{OCH}_{3}\right) .4 .05-4.22(\mathrm{~m}, 2 \mathrm{H}$. $\left.\mathrm{OCH}_{2}\right) .5 .09(\mathrm{~s}, \mathrm{lH}$. vinyl $\mathrm{CH}), 7.06-7.55(\mathrm{~m}, 5 \mathrm{H} . \mathrm{ArH})$. 7.37 (br s. IH. NH); IR (KBr) $3310(\mathrm{NH}) .1684(\mathrm{C}=\mathrm{O}), 1619$ $(\mathrm{C}=\mathrm{C}), 1154(\mathrm{C}-\mathrm{O}-\mathrm{C}), 1103(\mathrm{~S} \rightarrow \mathrm{O})$; Analysis Calcd for $\mathrm{C}_{13} \mathrm{H}_{17} \mathrm{NO}_{4} \mathrm{~S}: \mathrm{C}, 55.1$. H. 6.05, N, 4.94. Found, $\mathrm{C}, 55.2$. H. $6.03, \mathrm{~N}, 4.94$

Preparation of thiolsulfonate 22. To a stirred solution of thiolsulfinate $10(244 \mathrm{mg}, 0.5 \mathrm{mmnol})$ in acetone $(20 \mathrm{~mL})$ was added a solution of sodium periodate ( $128 \mathrm{mg} .0 .5 \mathrm{mmol}$ ) in water $(2 \mathrm{~mL})$. The reaction mixture was stirred at room temperature for $18 \mathrm{~h}$. The solvent was evaporated to give a white solid. This was dissolved in chloroform, washed with water. and dried $\left(\mathrm{Na}_{2} \mathrm{SO}_{4}\right)$. Evaporation of the solvent gave a white solid $(90 \mathrm{mg})$. Crystallization from acetone/petroleum ether gave $\mathbf{2 2}$ as a white amorphous solid (75 $\mathrm{mg} .30 \%$ ). $\mathrm{mp}$ $147-149{ }^{\circ} \mathrm{C}$ (crystallized from acetone/petroleum ether); ${ }^{1} \mathrm{H}$ NMR (200 MHz. $\left.\mathrm{CDCl}_{3}+\mathrm{DMSO}-d_{6}\right) 2.35$ and 2.36 (2s. $\left.6 \mathrm{H}, 2 \times \mathrm{CH}_{3}\right) .3 .52\left(\mathrm{t}, J=6.05 .2 \mathrm{H}, \mathrm{SCH}_{2}\right) .3 .90(\mathrm{t}, J=6.1 \mathrm{l}$. $\left.2 \mathrm{H}, \mathrm{SO}_{2} \mathrm{CH}_{3}\right) .4 .12\left(\mathrm{t}, J=6.05 .2 \mathrm{H}, \mathrm{OCH}_{2}\right) .4 .20(\mathrm{t} . J=6.1 \mathrm{l}$. $\left.2 \mathrm{H}_{2}, \mathrm{OCH}_{2}\right) .5 .33$ and $5.40(2 \mathrm{~s} .2 \mathrm{H}, 2 \times$ vinyl $\mathrm{CH}$ ). 6.98-7.61 (m. 10H, ArH). 8.95 and $9.05(2 \times$ br s, $2 \mathrm{H} .2 \times \mathrm{NH})$ : IR $(\mathrm{KBr}) 3298(\mathrm{NH}) .1669(\mathrm{C}=\mathrm{O}), 1319$ and $1126\left(\mathrm{SO}_{2}\right)$ : $\mathrm{MS}$ (70 eV) $\mathrm{mz}$ (relative intensity) $504.6\left(\mathrm{M}^{-}\right.$. not observed), $269\left(3.6, \mathrm{M}^{-}-\mathrm{S}=\mathrm{CHCH}_{3} \mathrm{OC}\left(\mathrm{CH}_{3}\right)=\mathrm{CHCONHC}_{6} \mathrm{H}_{5} .253(50.8\right.$. $\left.\mathrm{S}^{+}=\mathrm{CHCH}_{2} \mathrm{OC}\left(\mathrm{CH}_{3}\right)=\mathrm{CHCONHC}_{6} \mathrm{H}_{3}\right), 177\left(22.9 . \mathrm{CH}_{3} \mathrm{CO}^{-}\right.$ $\mathrm{CH}_{2} \mathrm{CONHC}_{6} \mathrm{H}_{5}$ ). 93 (100, $\mathrm{C}_{6} \mathrm{H}_{3} \mathrm{NH}_{2}{ }^{+}$); Analysis Calcd for $\mathrm{C}_{24} \mathrm{H}_{28} \mathrm{~N}_{2} \mathrm{O}_{6} \mathrm{~S}_{2}:$ C. 57.1, H, 5.59. N, 5.55. Found C. 57.1. $\mathrm{H}$, 5.61. N. 5.67 .

\section{References and Notes}

1. Lee. W. S.: Hahn. H. G.: Nam. K. D. J. Org. Chem. 1986. 51. 2789.

2. Hahn. H. G.: Lee, W. S. J. Chem Res. S 199586

3. Hogg. D. R. In Compwhensive Organic Chemisty, Jones, D. N.. Ed.: Pergamon Press. Ltd: Oxford. 1979: Vol. 3. pp 262-267.

4. Lee. W. S.: Park. O. S. J. Korean Chem. Soc. 1987.31. 197.

5. Hogg. D. R.: Vipond. P. W. J. Chent. Soc. (B) 1970. 1242: Hogg. D. R.; Stewart J. J. Chem. Soc. Penkin Trans $21974,43$.

6. Block. E. J.Am. Chem. Soc. 1972. 94, 642

7. Oae. S.; Takata. T.; Kim. Y. H. Temahedron Lett. 1977, 4219.

8. Oae. S.: Takata. T. Tetrohedron Lett. 1980.821.

9. It was reported that hydrolysis of a thiolsul finate in the presence of hydroxide ion affords a thiolsulfonate via -disul foxide. Similarly. the hydrolysis of a thiolsulfinate 10a in the presence of hydroside ion would afford the corresponding thiolsul fonate $\mathbf{2 2}$.

10. Kim. Y. H.; Takata. T.; Oae, S. Tetrahedron Lett. 1978, 2305: Oae. O.: Takata. T. Tetrahedhon Lett. 1980. 3213. 